\title{
Analysis and Prediction of Air Leakage through Door Assemblies
}

\author{
DANIEL GROSS \\ Center for Fire Research \\ National Bureau of Standards \\ Gaithersburg, Maryland 20899, USA
}

WILLIAM L. HABERMAN

Engineering Consultant

Rockville, Maryland, USA

\section{ABSTRACT}

A generalized relationship is presented for determining air flow rates through narrow gaps around door edges. The relationship provides values of leakage rates for steady, laminar flow through gaps over a wide range of pressure difference and eliminates approximations associated with the often inappropriate use of discharge coefficients and exponents in the flow equation $Q=C A(\Delta p)^{n}$. The analysis covers straight-through, single bend and double bend gaps of constant thickness, as well as connected gaps of constant thicknesses. Comparison of measured flow rates for installed stairwell door assemblies with those predicted by use of the relationship shows agreement within 20 percent. The volumetric flow of heated air through simple door gaps has been calculated by use of the relationship. The results show that the flow rate may increase or decrease with temperature depending on gap size and flow region.

\section{INTRODUCTION}

Prediction of the flow of air through gaps around exterior doors is of considerable importance in determining ventilation rates and heat losses in buildings. Knowledge of air leakage is also of importance in estimating the effectiveness of interior doors as barriers to smoke flow, and in the design of smoke control systems where stair and elevator shafts, vestibules, and other building spaces may be pressurized or exhausted. In the usual approach, use is made of an equation of the form $Q=C A(\Delta p)^{n}$ for describing flow through single gaps or through the multiple gaps of complete, closed door assemblies. Here, $Q$ is the volume flow rate, $C$ is a flow coefficient, $A$ is the cross-sectional area of the gap, $\Delta \mathrm{p}$ is the pressure drop across the gap, and $\mathrm{n}$ is an exponent. The constants $C$ and $n$ are generally not known or vary with gap geometry and Reynolds number. It has been noted that previous assumptions of $n=0.5$ (the square root approximation for thin plate orifices) are not always appropriate [1]. Nevertheless, it is common practice in smoke control design calculations to retain this assumption for all gaps or to utilize a value of $\mathrm{n}=0.5$ for large gaps and $\mathrm{n}=0.625$ for sma11 openings $[2,3]$.

The gaps in conventional door assemblies approximate deep (thickwalled) rectangular orifices, i.e. wide rectangular ducts, rather than thin-walled orifices for which typical discharge coefficients are often assumed. Such will be the case of a plain door at floor level, where there is no door stop, or at the meeting edges of swinging doors. In the more typical case, where there are simple stops, the flow passage may be considered a rectangular duct with a sharp $90^{\circ}$ bend or "e11". Where 
doors are rabbeted, the flow passage will be in the form of a double $90^{\circ}$ bend or "double el1". In addition, there may be recesses or cavities within the gap as well as variations in gap thickness, particularly in combination with $90^{\circ}$ bends. Finally, where sealing devices (flexible metal, rubber, or plastic strips, labyrinths, etc) are installed around the edges of doors or door frames to reduce air flow, the geometry of the flow passages may be quite complex. Air flow through straight-through gaps may be considered equivalent to aix flow in rectangular ducts, for which theory and experimental data are available [4-11]. Flow in such gaps is typically laminar but may also extend into the transition region at sufficiently high pressure differences.

Measuring air flow through very small, well-defined gaps involves setting up special apparatus including flow devices suitable for very low flow rates. Only a limited amount of experimental data has been published. The study by Hopkins and Hansford [1] provided data on flow through three simple gap configurations (straight-through, single bend and double bend). Homma [12] measured flow through straight-through gaps of various thicknesses and depths. Thomas and Dick [13] measured flow through short sections of steel and wood window assemblies. The configuration of these gaps is very similar to double bend gaps with enlarged center portions. Measurements for simple and complex gaps have also been reported by Ishira [14]; also, faired curves relating $\Delta p$ and volume flow rate through straight gaps and through a variety of complex gaps containing bends, recesses, and labyrinths are summarized in [15].

Standard measurements can be made of flow through door assemblies at several $\Delta$ p levels using a chamber, a fan or blower, and suitable flow control devices. Simple laboratory test methods have been in common use for exterior door and window assemblies where infiltration is of concern and where a standard pressure difference simulating wind pressure, e.g. $75 \mathrm{~Pa}$, is normally used [16]. More recently, it has been applied also to interior doors [17-20] where the principal concern is the control of potential leakage of smoke from building fires. A short review of the available air leakage measurements on interior door assemblies was published several years ago [21].

If $Q$ is plotted against $\Delta p$, a single value approximation of the exponent $\mathrm{n}$ is sometimes obtained in certain flow rate regions. Norma11y, full scale flow measurements of door assemblies are time-consuming and expensive, and this is especially true if heated air is used. Hence, it would be desirable to obtain a generalized relationship suitable for predictive calculations of air leakage through door gaps over a wide range of flow conditions. The purpose of this paper is to provide a relationship capable of predicting flow through gaps of prescribed geometry and to make comparisons with available experimental data on flow through gaps and around selected door assemblies.

\section{ANALYSIS}

\section{Flow in Straight-Through Gaps}

One distinguishing feature of the flow in gaps, unlike flow in ordinary pipe or duct installations, is the presence of a flow development region (Fig.1). The fluid which enters the gap is, due to viscosity, reduced to zero velocity along the entire gap wall. The fluid

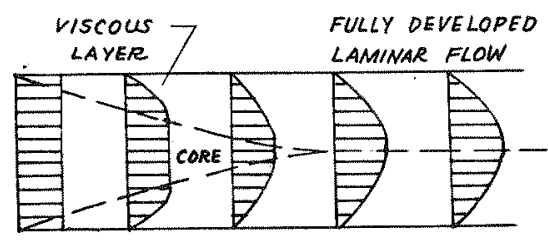

Fig 1 Development of Laminar Flow in a Gap 
layer at the wall gradually slows down the faster-moving fluid next to it, until the effect of viscosity is felt across the entire gap. In one model of flow development, it is assumed that the fluid enters with uniform velocity. In this case, the inviscid core region of uniform flow gradually disappears and is replaced by the fully developed flow. The flow development region often comprises a large portion of the flow through a gap.

To correlate data from a series of measurements, the use of nondimensional parameters based on the applicable set of physical variables becomes advantageous. The significance of using nondimensional parameters in lieu of dimensional ones lies in the reduction in the number of parameters required to describe the phenomenon. As a consequence, considerably fewer experimental measurements are required to establish a valid relationship between variables of the gap flow. An appropriate set of six significant physical variables is $Q=f\left(\Delta p, \rho, \nu, x, D_{h}\right)$, where $Q$ is the volume flow rate, $\Delta p$ is the pressure difference across the gap, $\rho$ is the fluid density, $\nu$ is the kinematic viscosity of the fluid, $x$ is the depth of gap in the flow direction, and $D_{h}$ is the hydraulic diameter. For rectangular gaps, $D_{h}=2 a$, where a is the thickness of the gap. Dimensional analysis was utilized to provide the following set of three nondimensional parameters: $C_{p}=f\left(R e, D_{h} / x\right)$, where $C_{p}$ is the pressure coefficient $\Delta \mathrm{p} /(1 / 2) \rho \mathrm{V}^{2}$ and $\mathrm{Re}$ is the Reynolds number $\mathrm{V} \mathrm{D}_{\mathrm{n}} / \nu$. Here, $\mathrm{V}$ (the average flow velocity) $=Q / L a=2 Q / L D_{h}$ for wide rectangular gaps.

The form of the analytic solution for laminar flow in the entrance region of rectangular ducts [7], where the pressure coefficient along the duct was related to the nondimensional parameter $\mathrm{x} / \mathrm{D}_{\mathrm{h}} \mathrm{Re}$, suggests a reduction in the number of parameters. Thus, the two parameters $\mathrm{Re}$ and $D_{h} / x$ were coalesced into one, namely Re $D_{h} / x$, yielding a simplified set containing only two parameters:

$C_{p}=f\left[\operatorname{Re} D_{h} / x\right]$

It should be emphasized that only a general functional dependency, not a specific functional relationship, (e.g. linear) is implied here.

The results of the analytic solution of Miller and Han [7] are shown in Fig.2, where the pressure coefficient $C_{p}$ for laminar flow in a wide rectangular duct is presented as a function of the parameter $\operatorname{Re} D_{h} / x$. Extensive experimental data on developing flow of air in wide rectangular ducts were obtained by Beavers et al [10] and cover the range in $\operatorname{Re} D_{h} / x$ from 20 to 2500. These data are also included in Fig.2. Excellent agreement between analytic and experimental results is noted. For values of Re $D_{h} / x$ less than 10 , the analytic solution merges into the straight line $96 \mathrm{x} / \mathrm{D}_{\mathrm{h}}$ Re, the solution for fully developed laminar flow in a wide rectangular duct. It should be noted that this straight line always lies below the developing flow curve; hence, the pressure drop in the entrance region of a duct will always be greater than that in an equal length of duct in fully developed flow. For short sections, the pressure drop in developing flow can be several times as great as that for fully developed flow. The analytic and experimental results do not contain entrance and leaving losses. Since there is inviscid flow to the gap entrance and a viscous jet leaving the gap, a combined entrance and leaving loss coefficient of 1.3 will be assumed. A curve for the total $C_{p}$ (the pressure drop in the duct plus entrance and leaving losses) has also been included in Fig.2. The reasonableness of the assumption will be confirmed by comparison with experimental data for straight-through gaps which includes such losses in its measurements. 


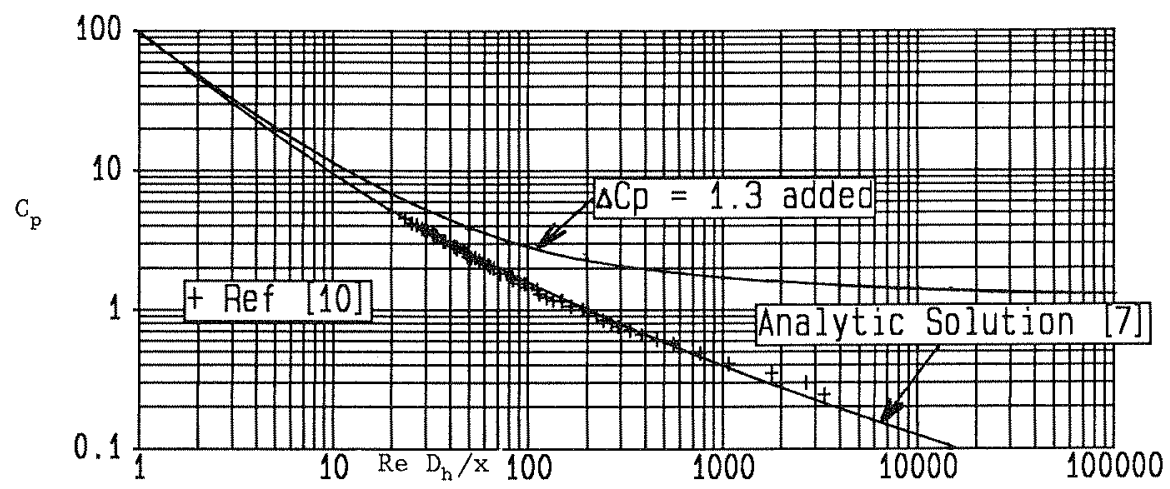

Fig 2 Pressure Coefficient for Wide Rectangular Ducts

Two previous studies of air flow in gaps $[1,22]$ sought to establish a simple correlation equation for the pressure coefficient $C_{p}$ using a linear exponent for the $\mathrm{x} / \mathrm{D}_{\mathrm{h}}$ Re parameter over the entire parameter range. This oversimplification leads to the anomalous result that, at large values of the parameter $x / D_{h}$ Re, the double-bend gap gives a lower pressure drop than that for the straight-through gap. As will be shown, no single slope is applicable over the entire parameter range. In this paper, we are proposing a different set of nondimensional parameters which are more appropriate to the problem of gap leakage, where it is usually required to find the fluid leakage rate for a given pressure difference. The proposed set consisting of three nondimensional parameters is $\mathrm{Q} / \mathrm{L} \nu=\mathrm{f}\left[\Delta \mathrm{pD}_{\mathrm{h}}{ }^{2} / \rho \nu^{2}, \mathrm{D}_{\mathrm{h}} / \mathrm{x}\right]$. Combining the products as suggested by the analytic results of Miller and Han [7], the number in the set is reduced to two parameters:

$\mathrm{QD}_{\mathrm{h}} / \mathrm{L} \nu \mathrm{x}=\mathrm{f}\left[\left(\Delta \mathrm{pD}_{\mathrm{h}}^{2} / \rho \nu^{2}\right)\left(\mathrm{D}_{\mathrm{h}} / \mathrm{x}\right)^{2}\right]$

Here $Q / L \nu=V a / \nu=1 / 2 D_{h} / \nu$ is a Reynolds number expressed in terms of the volume flow rate $\mathrm{Q}$. $\triangle \mathrm{p} \mathrm{D}_{\mathrm{h}}^{2} / \rho \nu^{2}$ is a viscous pressure coefficient which unlike the customary pressure coefficient $C_{p}=\Delta p / \frac{1}{2} p V^{2}$ contains no velocity term. The values of total $C_{p}$ and parameter $\operatorname{Re} D_{h} / x$ given in Fig. 2 were converted into values of the parameters $Q D_{h} / L \nu x$ and $\left(\Delta \mathrm{pD}_{\mathrm{h}}{ }^{2} / \rho \nu^{2}\right)\left(\mathrm{D}_{\mathrm{h}} / \mathrm{x}\right)^{2}$ and are shown as a solid curve in Fig. 3 together with the experimental data from References $[1,12,14]$ for straight-through gaps in terms of the new parameters. Three distinct regions may be noted. At low values of the dimensionless pressure difference (Region 1), the volume flow rate varies linearly with pressure difference, i.e. the slope is 1. At high values of pressure difference (Region 3 ), the volume flow rate varies with the square root of the pressure difference, i.e. the slope is 0.5. At intermediate pressure differences (Region 2), the exponent of the pressure difference varies from 0.5 to 1 .

For computer calculations, the following analytic expressions may be used to represent the relationship with engineering precision:

$\mathrm{NQ}=0.01042 \mathrm{NP}$

$\mathrm{NQ}=-3.305+0.2915 \mathrm{NP} \cdot{ }^{5}+0.01665 \mathrm{NP} \cdot{ }^{75}-0.0002749 \mathrm{NP}$

$\left.\begin{array}{r}\mathrm{NP} \leq 250 \\ 250<\mathrm{NP}<10^{6} \\ \mathrm{NP} \geq 10^{6}\end{array}\right\}$

$\mathrm{NQ}=0.555 \mathrm{NP} \cdot 5$

where $\mathrm{NQ}=\mathrm{QD}_{\mathrm{h}} / \mathrm{L} / \mathrm{x}$ and $\mathrm{NP}=\left(\Delta \mathrm{pD}_{\mathrm{h}}^{2} / \rho \nu^{2}\right)\left(\mathrm{D}_{\mathrm{h}} / \mathrm{x}\right)^{2}$ 


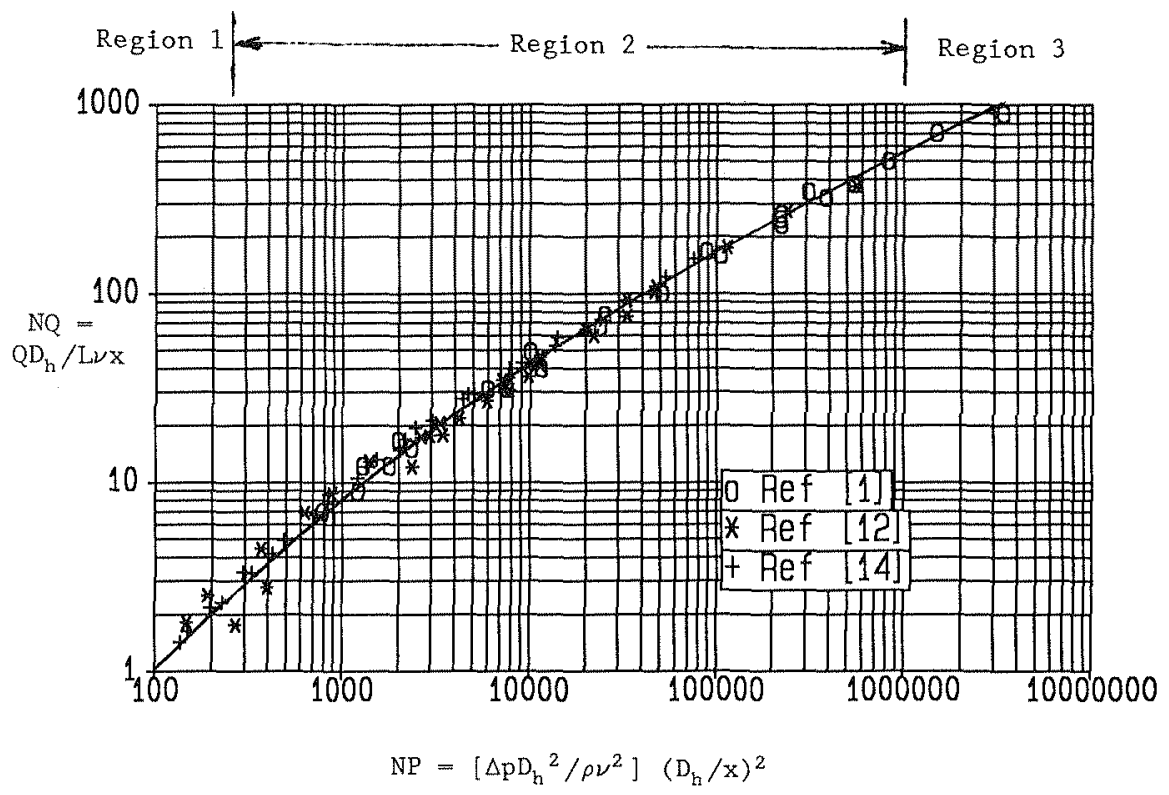

Fig 3 Nondimensional Q vs $\Delta$ p for Straight-Through Gaps

2. Flow in Gaps with Sharp $90^{\circ}$ Bends

In addition to the pressure drops due to skin friction within the gap and the entrance and leaving losses, it is sometimes necessary to include losses due to bends. The data of References [1] and [14] may be used to derive nondimensional relationships for wide rectangular gaps with one and with two sharp $90^{\circ}$ bends. These relations together with the appropriate data are shown in Fig.4. The relationships are essentially identical with that for the straight-through gap for values of NP up to 4000. The multiplication factors shown in the inset may be used in conjunction with Fig. 3 to obtain the appropriate values of NQ.

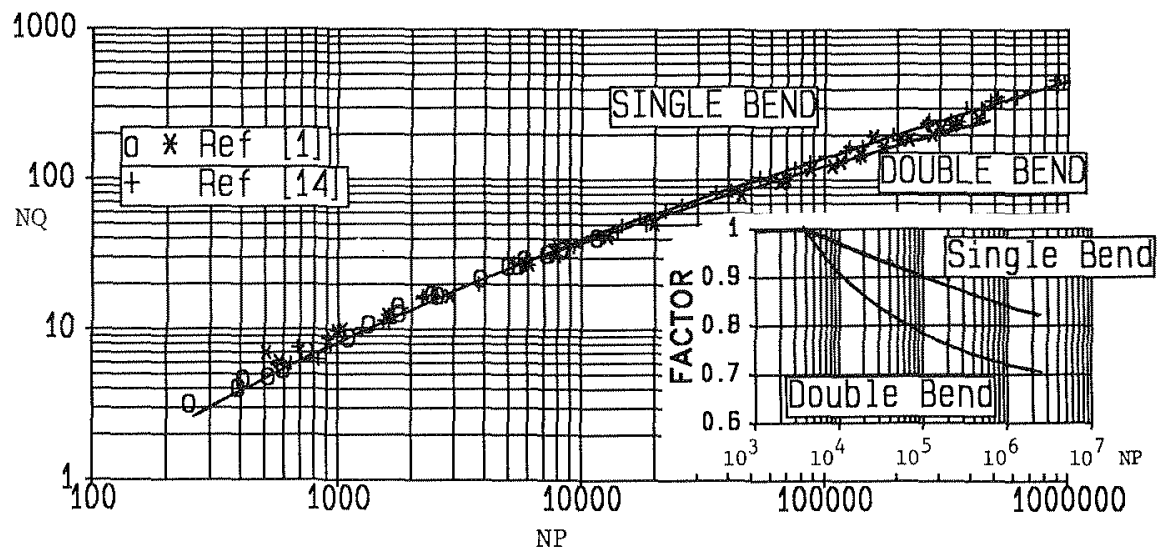

Fig 4 Nondimensional Q vs $\Delta$ p for Single and Double-Bend Gaps 


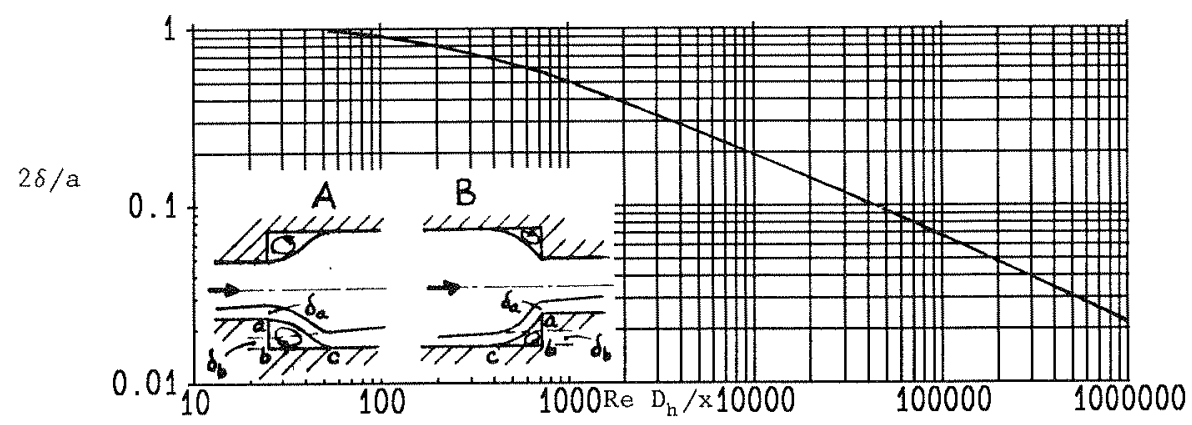

Fig 5 Boundary Layer Growth in Wide Rectangular Ducts

PREDICTION

1. Results for Connected Gaps with Different Thicknesses

The analytic solution of Miller and Han [7] was obtained for a uniform velocity distribution at the duct inlet. When an enlargement or contraction in the gap thickness occurs, the downstream section of the gap will experience a non-uniform velocity distribution at its inlet. Since no applicable analytical solutions are available, an approximation to such duct flows may be obtained by assuming that the boundary layer thickness at the enlargement or contraction remains unchanged. The variation in boundary layer thickness with the parameter $\operatorname{Re} D_{h} / x$ was derived from velocity distribution data given in [9] and from an analytic expression for the boundary layer thickness given in [23]. The restlt is shown in Fig.5. The approximation is based on the following consideration: As illustrated in Inset A of Fig.5, the flow entering an enlarged gap from a narrower gap will separate from the solid boundary and move along a free streamline until it reattaches itself to the solid boundary. The free streamline separates the main stream from the recirculating region. The boundary layer along a free streamline will grow at a lesser rate than if the surface were a solid boundary. The approximation assumes that the growth along the longer free streamline (ac) is equal to that obtained from the shorter solid boundary (bc) in the enlarged gap $\left(\delta_{\mathrm{a}}=\delta_{\mathrm{b}}\right)$. Similarly, as illustrated in Inset B of Fig.5, the flow ahead of a gap contraction will form a separated region in the wider gap. The approximation again assumes that the boundary layer growth along the free streamline is equal to that obtained by the shorter solid boundary.

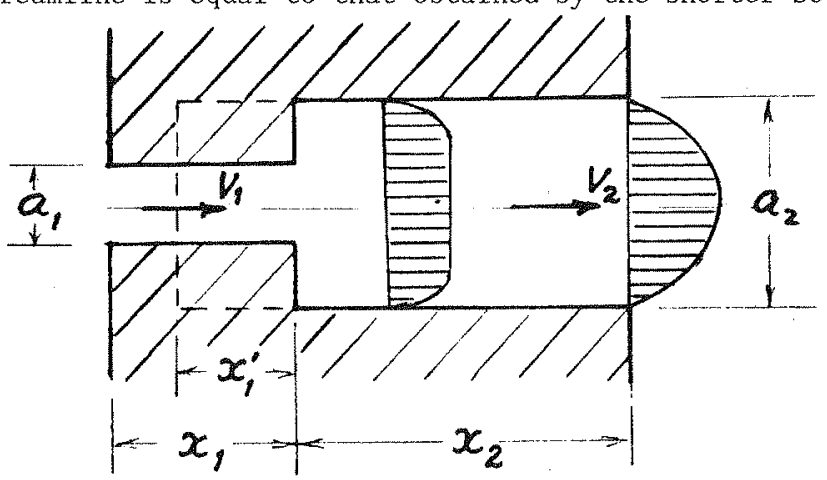

Fig 6 Series Flow in Gaps of Different Thickness 
Consider the flow through a gap consisting of a narrow section followed by a wider section as shown in Fig.6. In this case, it is not proper to add $C_{p}$ values for the two sections since each is based on a different fluid velocity; instead, corresponding $\Delta p$ values should be added. The following procedure is suggested as a reasonable approximation and is based on the assumption that the boundary layer thickness entering the second section is equal to that leaving the first section:

Step

(1) At $\operatorname{Re}\left(D_{h_{1}} / x_{1}\right)=\left(v_{1} D_{h 1} / \nu\right)\left(D_{h 1} / x_{1}\right)$, determine $\mathrm{C}_{\mathrm{p} 1}$ (Fig.2)

Galculate $\Delta \mathrm{p}_{1}=\mathrm{C}_{\mathrm{p} 1}\left(\frac{1}{2} \rho \mathrm{V}_{1}^{2}\right)$

(2) At $\operatorname{Re}\left(D_{h_{1}} / x_{1}\right)$, determine $2 \delta / a_{1}$ (Fig.5)

(3) At $2 \delta / a_{2}=\left(2 \delta / a_{1}\right)\left(a_{1} / a_{2}\right)$, determine $\operatorname{Re}\left(\mathrm{D}_{\mathrm{h} 2} / \mathrm{x}_{1}^{\prime}\right)$ (Fig. 5$)$

(4) At $\operatorname{Re}\left(\mathrm{D}_{\mathrm{h}_{2}} / \mathrm{x}_{1}{ }^{\prime}\right)$, determine $\mathrm{C}_{\mathrm{p} 1}{ }^{\prime}(\mathrm{Fig} .2)$ If the computed boundary layer thickness $(2 \delta / a)$ is $\geq 1$, use the relation $96 \mathrm{x}_{2} / \operatorname{Re} \mathrm{D}_{\mathrm{h} 2}$ to compute $\mathrm{C}_{\mathrm{p} 1}$ '

(5) At $\operatorname{Re}\left(D_{\mathrm{h}_{2}} /\left(\mathrm{x}_{1}^{\prime}+\mathrm{x}_{2}\right)\right)$, determine $\mathrm{C}_{\mathrm{p} 2}$

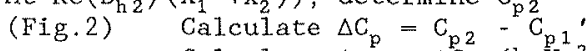
Calculate $\Delta \mathrm{p}_{2}=\Delta \mathrm{C}_{\mathrm{p}}\left(1 / 2 \mathrm{p}_{2}^{2}\right)$ Galculate $\Sigma \Delta \mathrm{p}=\Delta \mathrm{p}_{1}+\Delta \mathrm{p}_{2}$

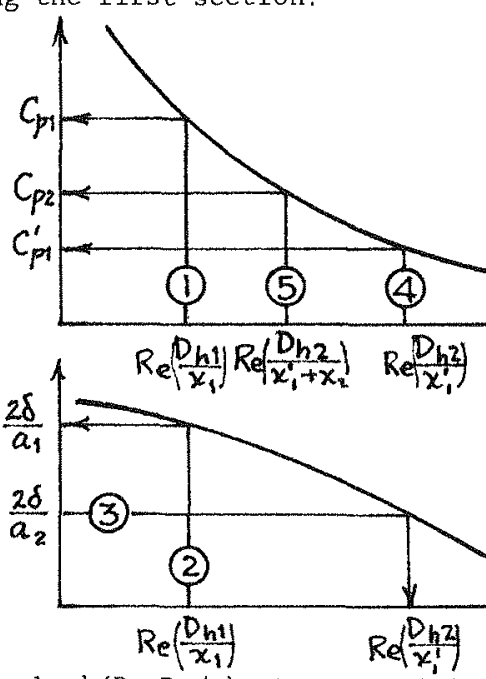

To convert the results to $\mathrm{QD}_{h} / \mathrm{L} \nu \mathrm{x}$ values, take $3_{2}\left(\mathrm{D}_{h} \mathrm{Re} / \mathrm{x}\right)$; to convert to $\left(\Delta \mathrm{pD}_{\mathrm{h}}^{2} / \rho \nu^{2}\right)\left(\mathrm{D}_{\mathrm{h}} / \mathrm{x}\right)^{2}$ values, multiply $\frac{1}{2} \mathrm{C}_{\mathrm{p}}$ by $\left(\operatorname{Re} \mathrm{D}_{\mathrm{h}} / \mathrm{x}\right)^{2}$.

Calculations have been made using this technique and have demonstrated that the upstream section is clearly the most critical in terms of pressure drop and flow. If a narrow thickness section precedes a larger section, the flow is considerably less than the flow in the reverse direction. As one example, the flow in a $38 \mathrm{~mm}$ long gap of $5 \mathrm{~mm}$ thickness will be reduced 81 if a $2 \mathrm{~mm}$ long gap of $1 \mathrm{~mm}$ thickness is added at the entrance (to provide a total gap length of $40 \mathrm{~mm}$ ), but will be reduced only 448 if the same $1 \mathrm{~mm}$ thick gap is placed at the exit. It is also of interest to note that for two sections of equal length, when the second section is larger than 3 times the thickness of the initial narrow section, the contribution of the larger section is very small and may be neglected with little exror.

\section{Results for Door Assemblies}

Reference [24] reported measurements of air leakage rates for stairwel1 door assemblies installed in eight high-rise buildings in Canada. To make predictions of the leakage rates, it is necessary to have detailed measurements of gap thicknesses and dimensions. These were kindly provided by Tamura [25]. The gaps were measured at three points along each vertical edge and at two points at the top and bottom edges of door assemblies using a series of metal shims. The shims were used in combination to provide measurements to the nearest $0.5 \mathrm{~mm}$, providing a reasonably good average for each door type. Along the vertical sides and the top edges of most door assemblies, the gaps consisted essentially of one long section plus one short $90^{\circ}$ section provided for the door stop. For analysis, this was considered as a single-bend, constant width gap with a path length equal to the sum of the two legs. All these measure- 
ments were combined to compute an average gap thickness from which a leakage flow, at a pressure difference of $25 \mathrm{~Pa}$, was computed from the relationships given in Figures 3 and 4 . The gap along the door bottom was considered separately since it is a straight-through gap, and in most cases was significantly thicker than the other gaps. The two partial flows were combined to yield an estimate of the total flow through the gaps around the door assembly. Similar predictions were made for comparison with measured leakage rates for door assemblies tested in the laboratory $[26,27]$. In cases where the gap consisted of a narrow section plus a considerably larger section, the latter was ignored since the bulk of the pressure drop occurs in the more constricted section. Table 1. contains a summary of the predicted and the measured air leakage rates at a pressure difference of $25 \mathrm{~Pa}$. In most cases, agreement between the predicted and measured flow rates was within 20 percent.

Table 1 Measured and Predicted Air Flow Rates through Door Assemblies

\begin{tabular}{|c|c|c|c|c|c|c|c|c|}
\hline \multirow[t]{2}{*}{ Source } & \multirow{2}{*}{\multicolumn{2}{|c|}{$\begin{array}{c}\text { Door } \\
\text { Designation }\end{array}$}} & \multirow{2}{*}{$\begin{array}{c}\text { Avg Gap } \\
\text { Thickness } \\
\text { mm }\end{array}$} & \multirow{2}{*}{$\begin{array}{l}\text { Gap } \\
\text { Depth }\end{array}$} & \multirow{2}{*}{$\begin{array}{l}\text { Gap } \\
\text { Length } \\
\mathbf{m}\end{array}$} & \multicolumn{3}{|c|}{$\frac{\text { Flow Rate }\left(\mathrm{m}^{3} / \mathrm{s}\right)}{\text { Predicted }}$ at $\Delta \mathrm{p}=25 \mathrm{~Pa}$} \\
\hline & & & & & & Component & Total & \\
\hline [24] & 1 & $\begin{array}{l}\text { Sides+Top } \\
\text { Bottom } \\
\text { Sides+Top } \\
\text { Bottom } \\
\text { Sides+Top } \\
\text { Bottom } \\
\text { Sides+Top } \\
\text { Bottom } \\
\text { Sides+Top } \\
\text { Bottom } \\
\text { Sides+Top } \\
\text { Bottom } \\
\text { Sides+Top } \\
\text { Bottom }\end{array}$ & $\begin{array}{r}3.06 \\
3.48 \\
2.40 \\
8.50 \\
2.95 \\
11.3 \\
2.62 \\
7.04 \\
2.19 \\
7.06 \\
2.91 \\
15.0 \\
2.95 \\
17.6\end{array}$ & $\begin{array}{l}74 \\
57 \\
55 \\
44 \\
57 \\
45 \\
55 \\
44 \\
58 \\
45 \\
55 \\
44 \\
56 \\
44\end{array}$ & $\begin{array}{l}5.17 \\
0.91 \\
5.17 \\
0.91 \\
5.17 \\
0.91 \\
5.17 \\
0.91 \\
5.90 \\
1.52 \\
5.17 \\
0.91 \\
5.17 \\
0.91\end{array}$ & $\begin{array}{l}0.053 \\
0.014 \\
0.044 \\
0.041 \\
0.058 \\
0.051 \\
0.048 \\
0.032 \\
0.043 \\
0.054 \\
0.057 \\
0.066 \\
0.057 \\
0.079\end{array}$ & $\begin{array}{l}0.067 \\
0.085 \\
0.109 \\
0.080 \\
0.097 \\
0.123 \\
0.136\end{array}$ & $\begin{array}{l}0.061 \\
0.080 \\
0.127 \\
0.076 \\
0.071 \\
0.104 \\
0.151\end{array}$ \\
\hline [26] & $\begin{array}{l}\text { A } \\
\mathrm{E}\end{array}$ & $\begin{array}{l}\text { Al1 edges } \\
\text { All edges }\end{array}$ & $\begin{array}{l}0.6 \\
1.45\end{array}$ & $60^{4.6}$ & $\begin{array}{l}6.0 \\
6.0\end{array}$ & - & $\begin{array}{l}0.013 \\
0.024\end{array}$ & $\begin{array}{l}0.013 \\
0.018\end{array}$ \\
\hline$[27]$ & 1 & $\begin{array}{l}\text { SidestTop } \\
\text { Bottom } \\
\text { Bottom only }\end{array}$ & $\begin{array}{l}1.0 \\
5.0 \\
7.0\end{array}$ & $\begin{array}{l}46 \\
48 \\
23\end{array}$ & $\begin{array}{l}4.88 \\
0.94 \\
0.91\end{array}$ & $\begin{array}{c}0.010 \\
0.023 \\
-\end{array}$ & $\begin{array}{l}0.033 \\
0.034\end{array}$ & $\begin{array}{l}0.050 \\
0.039\end{array}$ \\
\hline
\end{tabular}

\section{Effect of Air Temperature on Flow through Gaps}

In fire situations, knowledge of the flow of heated air or of a mixture of heated gases and smoke will be of interest. Moderately elevated temperatures up to at least 200 or $300^{\circ} \mathrm{C}$ may be anticipated on door assemblies which separate rooms and corridors or which serve as smoke or fire barriers in corridors or stairwells. For such door assemblies, where door deformation and warpage are small (below $300^{\circ} \mathrm{C}$ ), flow rates have been estimated as a function of temperature. For the simplest case of heated air, Table 2 lists values of the computed flow rates at selected temperatures and pressure differences. These values were computed using the relationship shown in Fig 3 for straight-through gaps and the values for density and kinematic viscosity of dry air 1 isted in Table 2. It is of interest to note that due to the decrease in density and the increase in kinematic viscosity of air with temperature, the flow rate may increase, decrease, or remain essentially constant as temperature increases, depending on the flow regions involved (see Table 2). 
Table 2 Effect of Air Temperature through a Straight Gap (Depth-40 mm)

\begin{tabular}{|c|c|c|c|c|c|c|c|}
\hline$\stackrel{\Delta \mathrm{p}}{\mathrm{Pa}}$ & ${ }^{\text {Temp }}{ }_{\mathrm{C}}$ & $\begin{array}{c}\text { Density } \\
\mathrm{kg} / \mathrm{m}^{3}\end{array}$ & $\begin{array}{l}\text { Viscosity } \\
10^{5} \mathrm{~m}^{2} / \mathrm{s}\end{array}$ & $\begin{array}{l}\text { Flow (m } \\
0.5 \mathrm{~mm}\end{array}$ & $\begin{array}{l}\mathrm{s} \mathrm{m}) \text { for } \\
1.0 \mathrm{~mm}\end{array}$ & $\begin{array}{l}\text { Gap Thick } \\
5.0 \mathrm{~mm}\end{array}$ & $\begin{array}{l}e s s(a) \\
10.0 \mathrm{~mm}\end{array}$ \\
\hline 10 & $\begin{array}{r}20 \\
100 \\
300\end{array}$ & $\begin{array}{l}1.204 \\
0.946 \\
0.616\end{array}$ & $\begin{array}{l}1.51 \\
2.30 \\
4.75\end{array}$ & $\begin{array}{l}0.000144 \\
0.000121 \\
0.000088\end{array}$ & $\begin{array}{l}0.00106 \\
0.000938 \\
0.000703\end{array}$ & $\begin{array}{l}0.0146 \\
0.0162 \\
0.0185\end{array}$ & $\begin{array}{l}0.0323 \\
0.0362 \\
0.0435\end{array}$ \\
\hline 25 & $\begin{array}{r}20 \\
100 \\
300\end{array}$ & $\begin{array}{l}1.204 \\
0.946 \\
0.616\end{array}$ & $\begin{array}{l}1.51 \\
2.30 \\
4.75\end{array}$ & $\begin{array}{l}0.000358 \\
0.000299 \\
0.000223\end{array}$ & $\begin{array}{l}0.00227 \\
0.00212 \\
0.00173\end{array}$ & $\begin{array}{l}0.0243 \\
0.0267 \\
0.0314\end{array}$ & $\begin{array}{l}0.0507 \\
0.0570 \\
0.0703\end{array}$ \\
\hline 100 & $\begin{array}{r}20 \\
100 \\
300\end{array}$ & $\begin{array}{l}1.204 \\
0.946 \\
0.616\end{array}$ & $\begin{array}{l}1.51 \\
2.30 \\
4.75\end{array}$ & $\begin{array}{l}0.00138 \\
0.00117 \\
0.000887\end{array}$ & $\begin{array}{l}0.00628 \\
0.00612 \\
0.00591\end{array}$ & $\begin{array}{l}0.0507 \\
0.0569 \\
0.0678\end{array}$ & $\begin{array}{l}0.1012 \\
0.1150 \\
0.1425\end{array}$ \\
\hline
\end{tabular}

\section{FURTHER REMARKS}

1. The experimental data and examples have dealt with air as the fluid at ambient and elevated temperatures. In actual situations, the fluid may be a mixture of heated combustion products, e.g. nitrogen, carbon dioxide, water vapor, hydrocarbons, etc rather than dry air. Since the analysis applies to any fluid, values of density and kinematic viscosity appropriate for the actual mixture should be used.

2. In other situations, the fluid may consist of multiple phases, i.e. gases, condensed vapors, solid particulates. Unfortunately, no analytical work appears to be currently available dealing with multiple-phase flow in the entrance region of a gap.

3. The described predictive procedure for estimating the pressure losses for developing flow in connected rectangular gaps (sudden enlargement and contraction) is an approximation. Experimental data on flow through such gaps over a wide range of flow parameters are needed for confirmation.

4. The pressure difference acting on a door assembly may vary with height and with time rather than being uniform and constant. In a typical room involved in a fire (or otherwise heated), positive pressures relative to the exterior will exist over the upper $1 / 2$ or $2 / 3$ of the door height and negative pressures below. This situation can be treated by considering the vertical gaps to consist of multiple segments. The total flow can then be obtained by summing up the contributions of the individual segments.

5. Gaps between doors and frames may not be of simple geometric shape and may contain special sealing devices, including flexible gaskets, fiber brushes, etc. In such situations, standard laboratory testing or special research studies may be needed to define leakage flows properly.

\section{CONCLUSIONS}

The generalized relationship presented in graphical and analytical form in this paper permits prediction of fluid flow through gaps of constant thickness over a wide range of pressure difference, with direct application to leakage of air or heated combustion products through gaps in door assemblies. In addition, a procedure is proposed for extending the predictive capability to the flow through connected gaps with different thicknesses. In the design of pressurized or exhausting smoke control systems, this relationship provides a more accurate means of predicting air flow through door assemblies than the simplified equation $\mathrm{Q}=\mathrm{CA}(\Delta \mathrm{p})^{\mathrm{n}}$ currently in use. 


\section{REFERENCES}

1. Hopkins, L.P. and Hansford, B. "Air Flow Through Cracks" Build. Serv. Engr. Vo1. 42, 123-29 (Sept. 1974).

2. Butcher, E.G. and Parnel1, A.C. Smoke Control in Fire Safety Design E. \& F.N. Spon Publishers, London (1979).

3. Kiote, J.H. and Fothergil1, J.W. Design of Smoke Control Systems for Buildings, American Society of Heating, Refrigeration and Air Conditioning Engineers, Atlanta (1983)

4. Fleming, D.P. and Sparrow, E.M. "Flow in the Hydrodynamic Entrance Region of Ducts of Arbitrary Cross Section" J. Heat Transfer Vol. $91,345-54(1964)$.

5. Han, L. S. "Hydrodynamic Entrance Lengths for Incompressible Laminar in Rectangular Ducts" J. App1. Mech. Vol. 27, 403-9 (1960).

6. Wiginton, C.L. and Dalton, C. "Incompressible Laminar Flow in the Entrance Region of a Rectangular Duct" J. App1. Mech. Vo1. $37854-56$ (1970).

7. Miller, R.W. and Han, L.S. "Pressure Losses for Laminar Flow in the Entrance Region of Ducts of Rectangular and Equilateral Triangular Cross Section" J. App1. Mech. Vol. 38, 1083-87 (1971).

8. Tachibana, M. and Iemoto, Y. "Steady Laminar Flow in the Inlet Region of Rectangular Ducts" Bulletin of the JSME Vo1. 24, No. 193 (1981).

9. Sparrow, E.M., Hixon, C.W. and Shavit, G. Experiments on Laminar Flow Development in Rectangular Ducts" J. Basic Eng. Trans. ASME Vo1. 89D, 116-24 (1967).

10. Beavers, G.S. Sparrow, E.M. and Magnuso, R.A. "Experiments in Hydrodynamically Developing Flow in Rectangular Ducts of Arbitrary Aspect Ratio" Int. J. of Heat Mass Transfer Vol.13, 689-702 (1970).

11. Shah, R.K. and London, A.L. "Laminar Flow Forced Convection in Ducts" Chapter VII, Advances in Heat Transfer, Academic Press, New York $(1978)$.

12. Homma, $H$. "Ventilation of Dwellings and its Disturbances" Tech. Rpt. 63, Swedish Inst. Heating and Ventilation (1975).

13. Thomas, D.A. and Dick, J.B. "Air Infiltration Through Gaps Around Windows" $j$. Inst. Heating and Ventilating Engrs, Vol. 85-97 (June $1953)$.

14. Ishira, M. "Leakage Coefficients of Gaps", Japan Arch. Soc. Rpt. 29 (1954).

15. Ventilation Design Handbook \# 18, Japan Arch. Soc, 10th Edition $(1980)$

16. ASTM E283-84 "Standard Test Method for Rate of Air Leakage through Exterior Windows, Curtain Walls, and Doors", ASTM, Philadelphia $(1984)$.

17. ISO 5925/1 "Fire Tests - Evaluation of Performance of Smoke Control Door Assemblies - Part 1: Ambient Temperature Test" Iso (1981).

18. NFPA 105 "Instaliation of Smoke-and Draft-Control Door Assemblies", National Fire Protection Association (1985).

19. BS 476: Part 31 "Methods for Measuring Smoke Penetration through Doorsets and Shutter Assemblies; Ambient Temperature Conditions" (1983)

20. DIN 18095 "Smoke Control Doors; Definitions and Requirements" Deutsches Institut fur Normung (1983).

21. Gross, D. "A Review of Measurements, Calculations and Specifications of Air Leakage Through Interior Door Assembles", Build, Standards, Vol. L, No. 2 11-16 (1981).

22. Etheridge, D.W. "Crack Flow Equations and Scale Effect" Build. and Envir. Vol. i2, 181-9 (1977).

23. Hahnemann, $H$. and Ehret, L. "Pressure Losses for Laminar Flow in the Entrance Region of Straight, Plane Gaps" Jahrbuch der Deutschen Luftfahrtforschung $121-32$ (1941).

24. Tamura, G.T. and Shaw, C.Y. "Air Leakage Data for the Design of Elevators and Stair Shaft Pressurization Systems" ASHRAE Trans. Vol. 81 (1975)

25. Tamura, G.T., Division of Building Research, National Research Council of Canada, Personal Communication (1983).

26. Poulsen, P.E. "Smoke Control Doors Test Report" Danish Nat Inst for Testing of Materials, Copenhagen (1979).

27. Westhoff, $W$. and Ueberal1, T. "Results of Tests for Performance of Smoke Control Door Assemblies at Ambient and Medium Temperatures" Federal Materials Testing Laboratory, Dortmund (1979). 